\title{
Evaluation of Silver Nanoparticle Encapsulation in DPPC-Based Liposome By Different Methods For Enhanced Cytotoxicity
}

\author{
Azeez O. Yusef \\ Technological University Dublin \\ Alan Casey \\ Technological University Dublin, alan.casey@tudublin.ie
}

Follow this and additional works at: https://arrow.tudublin.ie/scschphyart

Part of the Nanoscience and Nanotechnology Commons

\section{Recommended Citation}

Yusef, A.O. and Casey, A. (2019). Evaluation of silver nanoparticle encapsulation in DPPC-based liposome by different methods forenhanced cytotoxicity. International Journal of Polymeric Materials , June 2019 doi:10.1080/00914037.2019.1626390

This Article is brought to you for free and open access by the School of Physics \& Clinical \& Optometric Science at ARROW@TU Dublin. It has been accepted for inclusion in Articles by an authorized administrator of ARROW@TU Dublin. For more information, please contact arrow.admin@tudublin.ie, aisling.coyne@tudublin.ie, gerard.connolly@tudublin.ie.

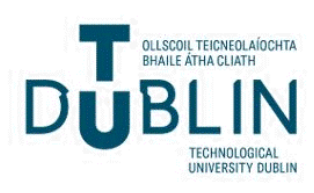




\title{
Evaluation of silver nanoparticle encapsulation in DPPC-based liposome by different methods for enhanced cytotoxicity
}

\author{
Azeez O. Yusuf, and Alan Casey \\ QUERY SHEET
}

This page lists questions we have about your paper. The numbers displayed at left are hyperlinked to the location of the query in your paper.

The title and author names are listed on this sheet as they will be published, both on your paper and on the Table of Contents. Please review and ensure the information is correct and advise us if any changes need to be made. In addition, please review your paper as a whole for typographical and essential corrections.

Your PDF proof has been enabled so that you can comment on the proof directly using Adobe Acrobat. For further information on marking corrections using Acrobat, please visit http://journalauthors.tandf.co.uk/production/acrobat.asp; https://authorservices.taylorandfrancis.com/how-to-correct-proofs-with-adobe/

The CrossRef database (www.crossref.org/) has been used to validate the references.

\section{AUTHOR QUERIES}

No Queries 


\section{Evaluation of silver nanoparticle encapsulation in DPPC-based liposome by different methods for enhanced cytotoxicity}

Azeez O. Yusuf ${ }^{\mathrm{a}, \mathrm{b}}$ and Alan Casey ${ }^{\mathrm{a}, \mathrm{b}}$

${ }^{a}$ School of Physics, Dublin Institute of Technology, Dublin, Ireland; ${ }^{b}$ Nanolab Research Centre, FOCAS Research Institute, Dublin Institute of Technology, Dublin, Ireland

\begin{abstract}
Here we carried out a comparative study on two cost and time effective methods of encapsulating silver nanoparticles (AgNP) in dipalmitoyl-phosphatidyl choline (DPPC)/cholesterol-based liposome to enhance its cytotoxicity and reduce cytotoxic concentrations and evaluated the effect of this on a blood cell line (THP1 monocytes) often involved in uptake of nanoparticles during human exposure. DLS and Zeta potential analyses over a 6-months period showed the extruded LipoAgNP (ExLipo-AgNP) exhibited more stable characteristics when compared with the probe-sonicated Lipo-AgNP (PB-Lipo-AgNP). SEM microscopy indicated agglomeration of the PB-Lipo-AgNP which was not observed in Ex-Lipo-AgNP. Ex-Lipo-AgNP also exhibited higher temperaturedependent stability with $35.3 \%$ reduction in size from $20^{\circ} \mathrm{C}$ to $37^{\circ} \mathrm{C}$ while PB-Lipo-AgNP was less stable exhibiting $55 \%$ size reduction over same temperature range. Load release study over $24 \mathrm{~h}$ showed a controlled load release from Ex-Lipo-AgNP while the PB-Lipo-AgNP exhibited burst release at $\mathrm{pH} 4$ and 6.5. Interestingly, it was found that Ex-Lipo-AgNP induced significantly higher toxicity on THP1 cell line after $24 \mathrm{~h}$ exposure compared with control unexposed cells; uncoated AgNP and PB-Lipo-AgNP exposed cells at the same concentration. Thus, for the first time, we report that liposomal encapsulation of AgNP by extrusion produces a stable nanocapsule with enhanced cytotoxicity, thus preventing overreliance on high AgNP concentration to achieve desired toxicity.
\end{abstract}

\section{GRAPHICAL ABSTRACT}

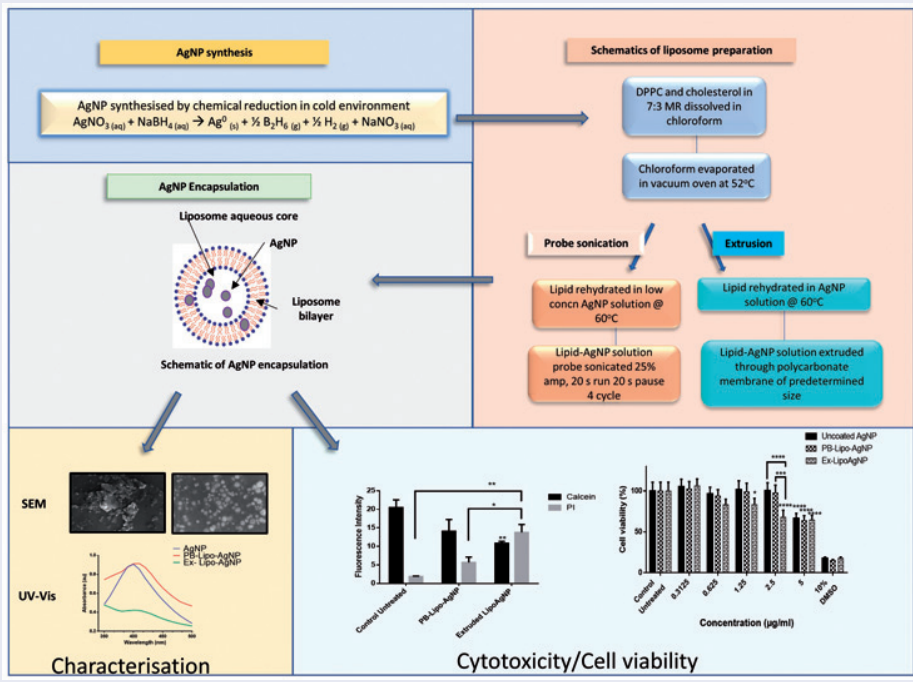

\section{ARTICLE HISTORY}

Received 21 March 2019

Accepted 29 May 2019

\section{KEYWORDS}

Silver nanoparticle (AgNP); encapsulation;

liposome; extrusion

\section{Introduction}

Silver nanoparticles (AgNP) are a widely used nanoparticle for its antibacterial activities and many of the already commercialized products contain AgNP in high concentrations as the active ingredient. For example, AgNP is widely used as antibacterial coating on medical garments and surgical 108 equipment and even on food materials to prolong shelf life 109 by preventing food degradation consequent upon bacterial 110

CONTACT Azeez 0. Yusuf Azeez.yusuf1@mydit.ie $\mathbf{O}$ School of Physics, Dublin Institute of Technology, Kevin Street, Dublin 8, Ireland; $\mathbf{0}$ Nanolab Research Centre, FOCAS Research Institute, Dublin Institute of Technology, Kevin Street, Dublin 8, Ireland.

Color versions of one or more of the figures in the article can be found online at www.tandfonline.com/gpom. 
metabolism and growth ${ }^{[1,2]}$. In addition, AgNP are currently being investigated by different studies as a chemotherapeutic in cancer treatment ${ }^{[3-6]}$. Unfortunately, with the rise in the biomedical applications of AgNP, development of adverse conditions due to repeated human exposure to AgNP is imminent either from direct contact with products containing AgNP or AgNP that has leached into the ecosystem. AgNP has been reported to cause several adverse effects such as skin irritation and discoloration, hepatotoxicity, kidney damage, DNA damage and epithelia cell damage ${ }^{[7]}$.

Adverse reactions of conventional drugs are not uncommon and improvement on the delivery mechanisms has been a major way to limit these setbacks. For AgNPs however, there has been little or no research into how to improve upon the delivery mechanism to enhance their antibacterial or anticancer activities. The applications of liposomes in drug delivery systems (DDS) have been studied for more than two decades and there have been significant improvements in the formulations and methods by which liposome are prepared. For instance, phosphatidyl choline (PC) based lipids are highly used in liposome preparation likely due to the fact that PC makes up about $80 \%$ of the surfactants found on epithelial lining of human airways and lungs. Interestingly, the majority of the PC in the human airways is present in the form of dipalmitoylphosphatidyl choline (DPPC), and this makes up about $60 \%$ of the natural surfactants found in the human airways and lungs ${ }^{[8]}$. Consequently, DPPC is highly unlikely to elicit immune response when incorporated in a liposomal formulation compared to the other derivatives.

Liposomes are designed to mimic the lipid bilayer of the cell membrane and while the natural bilayer of the cell membrane is made up different phospholipids, they also contain cholesterol molecules that help restrict the movement of the fluid phospholipid molecules. In the same manner, it has been shown that cholesterol, when incorporated in liposomal formulations at the right concentration can produce such rigidity to protect the liposomal content ${ }^{[9]}$. In this study, AgNP synthesized by chemical reduction of silver nitrate $\left(\mathrm{AgNO}_{3}\right)$ using sodium borohydride $\left(\mathrm{NaBH}_{4}\right)$ was encapsulated in a DPPC/cholesterol liposome to both stabilize and improve the uptake of the AgNP in vitro for enhanced cytotoxicity. Two simple encapsulation methods were trialed AgNP, followed by nanoparticle characterization and evaluation of cytotoxicity on a THP1 cell line, a monocytic cell line which acts as first line of Defense against nanoparticle during exposure ${ }^{[10]}$.

\section{Materials and methods}

\subsection{Chemicals and reagents}

Silver nitrate $\left(\mathrm{AgNO}_{3}\right)$, sodium borohydride $\left(\mathrm{NaBH}_{4}\right)$, DPPC, cholesterol, Phorbol 12-myristate 13-acetate (PMA) and propidium iodide (PI) were purchased from Sigma Aldrich, Dublin, Ireland while chloroform, Calcein-AM dye and Alamar blue (AB) were from ThermoFischer Scientific, Dublin, Ireland.

\subsection{AgNP synthesis}

To synthesize AgNP, $6 \mathrm{~mL}$ of $1 \mathrm{mM}$ of $\mathrm{AgNO}_{3}$ solution was added dropwise into an Erlenmeyer flask containing magnetic stirrer a $350 \mathrm{rpm}$ and ice cold $30 \mathrm{~mL}$ of $2 \mathrm{mM}$ of $\mathrm{NaBH}_{4}$. The stirring was continued until last drop when the stirrer was removed for the solution to turn golden yellow. The obtained AgNP was characterized by UV/Vis in a Spectramax M2 microplate reader while atomic absorption spectrophotometry (AAS) was employed to monitor silver (Ag) concentration using a SpectrAA200 Varian Spectrophotometer (Mulgrave, VC, Australia). The samples were analyzed with a silver hollow cathode lamp at an operating current of $7.5 \mathrm{~mA}$. Hydrodynamic size of AgNP and liposomal AgNP (Lipo-AgNP) was carried out with Malvern Zetasizer Nano ZS (Malvern Panalytical, Malvern, UK). Nanoparticles were loaded into a prerinsed folded capillary cell up to the marked portion. For zeta potential, an applied voltage of 15 and $50 \mathrm{~V}$ was used for Lipo-AgNP and free AgNP respectively.

\subsection{Liposome synthesis, AgNP encapsulation and characterization}

Liposome was prepared by probe sonication and extrusion methods. DPPC and cholesterol were weighed in a mass ratio such that eventual rehydration of the lipid film obtained will give a 7:3 molar ratio solution respectively. The lipids were dissolved in a fixed amount of chloroform and mixed until the mixture becomes clear. The resulting solution was placed in a vacuum oven set at $52{ }^{\circ} \mathrm{C}$ for the chloroform to evaporate.

\subsubsection{Probe sonication method}

The lipid cake formed was then rehydrated in AgNP solution at $60^{\circ} \mathrm{C}$. AgNP solution were added to the lipid at 1:300 (w/w) of AgNP:DPPC after which the solution was vortexed briefly for $2 \mathrm{~min}$ to form multi-lamellar vesicles (MLV). The mixture was probe sonicated at $21 \%$ amplitude, $20 \mathrm{~s}$ run and $20 \mathrm{~s}$ pause for 4 cycles to form Small Uni-lamellar Vesicles (SUV). The resultant mixture was then centrifuged at $800 \times g$ for $10 \mathrm{~min}$ at $4{ }^{\circ} \mathrm{C}$ to remove any MLVs. The suspension was subjected to DLS and zeta potential analysis for size and stability measurements respectively.

\subsubsection{Extrusion method}

The lipid film was rehydrated in $\mathrm{AgNP}$ solution at $60^{\circ} \mathrm{C}$ to make the final concentration at 1:300 (w/w) of AgNP:DPPC. The solution was placed in the shaker at $60^{\circ} \mathrm{C}$ on $140 \mathrm{rpm}$ for another $20 \mathrm{~min}$ after which it was vortexed briefly for $2 \mathrm{~min}$ to form multi-lamellar vesicles (MLV). This was then extruded through a $100 \mathrm{~nm}$ "Nanosizer" polycarbonate extruder purchased from T\&T Scientific (Knoxville, USA). The suspension was subjected to DLS and zeta potential analysis for size and stability measurements respectively. 


\subsection{Temperature-dependent size measurements, stability tests and $\mathrm{pH}$-dependent drug release study}

To check the effect of incubation conditions on the nanocapsules, both probe-sonicated (PB-Lipo-AgNP) and ExLipo-AgNP were subjected to temperature dependent size stability tests. This was done by preparing a solution LipoAgNP in $10 \%$ fetal bovine serum (FBS) supplemented RPMI-1640 and subjecting them to DLS size measurements over a temperature range of $20^{\circ} \mathrm{C}-38^{\circ} \mathrm{C}$ with $1{ }^{\circ} \mathrm{C}$ increments of temperature.

For nanoparticle stability determination, variations in nanoparticles mean size and zeta potential of both Ex-LipoAgNP and PB-Lipo-AgNP were measured at a specific interval over a period of 6 months at both $4^{\circ} \mathrm{C}$ (storage temperature) and $24^{\circ} \mathrm{C}$ (room temperature). $5 \mathrm{~mL}$ of PB-Lipo-AgNP and Ex-Lipo-AgNP were incubated at $4{ }^{\circ} \mathrm{C}$ and $24^{\circ} \mathrm{C}$ and $1 \mathrm{~mL}$ sample was taken at each time point for analyses at specific time interval.

For $\mathrm{pH}$ dependent AgNP release from the nanocapsules, $1 \mathrm{~mL}$ of the encapsulated AgNP was added into a FLOATA-LYZER G2 CE dialysis tube with a $1000 \mathrm{KDa}$ MW cut off (Spectrum Labs, Breda, Netherlands). The dialysis tube was placed in $6 \mathrm{~mL}$ of either an acetate buffer $(\mathrm{pH} 6.5)$ or a phosphate buffer saline (PBS) at $\mathrm{pH} 7.45$. The ratio between the inside and outside volumes were maintained as thus to facilitate easy movement of the AgNP as recommended by Shen and Burgess ${ }^{[11]}$. The tube was then placed on a shaker running a $300 \mathrm{rpm}$ at $37^{\circ} \mathrm{C}$. To measure the amount of AgNP released, $200 \mu \mathrm{L}$ of Lipo-AgNP sample was taken from the dialysis tube at specific time interval for $24 \mathrm{~h}$ and the absorbance was measured in the SpectraMax M2 microplate reader at $405 \mathrm{~nm}$. After absorbance measurement, the measured sample was replaced with a fresh buffer to avoid change in volume and sink condition.

\subsection{Scanning electron micrograph (SEM) and scanning transmission electron micrograph (STEM) analysis}

SEM micrographs were obtained for both AgNP and LipoAgNPs. Briefly, both PB-Lipo-AgNP and Ex-Lipo-AgNP were microscopically analyzed using Hitachi SU-6600 field emission SEM (Hitachi, Maidenhead, UK) with accelerating voltage of $25 \mathrm{kV}$ and $8 \mathrm{~mm}$ working distance. At $24 \mathrm{~h}$ before analysis was carried out, $5 \mu \mathrm{L}$ of sample was drop-cast to air dry onto a $5 \times 5 \mathrm{~mm}$ pure silicon wafer substrate (Ted Pella Inc., Redding, California, USA) for SEM or carbon formvar copper grid (Agar Scientific Ltd., Stanstead, UK) for STEM, before micrographs were obtained.

\subsection{Estimating encapsulation efficiency of the liposome}

To estimate the encapsulation efficiency, both probe-sonicated and extruded Lipo-AgNP were centrifuged at 20,000 $\times g$ for $1 \mathrm{~h}$ and the supernatant was harvested. The supernatant was then analyzed by atomic absorption spectrophotometry to estimate the concentration of silver in the solution. The encapsulation efficiency $(E)$ of the liposome 292 was then calculated using the formula below 293

$\mathrm{E}=\frac{\text { Total AgNP added to liposome-AgNP in supernatant }}{\text { Total AgNP added to liposome }} \times 100295$

297

2.7. Cell culture and alamar blue cell viability

298

299

THP1 (ATCC ${ }^{\circledR}$ : TIB-202 ${ }^{\mathrm{TM}}$ ) used for this study were cul- 300 tured in RPMI-1640 media supplemented with $2 \mathrm{mM} \mathrm{L-glu-} 301$ tamine and $10 \%$ FBS. The cells were incubated at $37^{\circ} \mathrm{C}, 302$ $95 \%$ humidity and $5 \% \mathrm{CO}_{2}$. For nanoparticle exposure, cells 303 were seeded in a 24 -well plate (VWR, Dublin, Ireland) at a 304 density of $3 \times 10^{5}$ cells $/ \mathrm{mL}$ in media containing $100 \mathrm{ng} / \mathrm{mL} 305$ PMA for a $24 \mathrm{~h}$ to induce adherence to the plate. After this, 306 the culture media containing PMA was removed from the 307 now adhered monocytic THP1 cells and replaced with fresh 308 RPMI media containing different concentrations of uncoated 309 AgNP, PB-Lipo-AgNP and Ex-Lipo-AgNP. A positive kill 310 control of cells exposed to dimethyl sulfoxide (DMSO) solu- 311 tion $(10 \% \mathrm{v} / \mathrm{v})$ in RPMI media incorporated onto the plate. 312 A minimum of three independent experiments were con- 313 ducted and for each independent experiment, four replicate 314 wells were employed per concentration per plate.

To evaluate cell viability post-exposure a pre-warmed 316 $10 \% \mathrm{AB}$ solution in serum free media was prepared. The 317 exposure media were removed, and the cells were rinsed 318 with prewarmed sterile $1 \times$ phosphate buffer saline (PBS) 319 after which $1.5 \mathrm{~mL}$ of $\mathrm{AB}$ solution was added onto the cells 320 and incubated at $37^{\circ} \mathrm{C}$ for $2 \mathrm{~h}$. The resulting florescence of 321 the converted $\mathrm{AB}$ dye was measured at $540 \mathrm{~nm}$ excitation 322 and $595 \mathrm{~nm}$ emission and excitation wavelengths in a 323 $\begin{array}{ll}\text { SpectraMax }^{\circledR} \text { M2 Multi-Mode Microplate Reader. } & 324 \\ & 325\end{array}$

\subsection{Flow cytometry}

THP1 cells were seeded and cultured in T25 flasks at 328 $2 \times 10^{5}$ cells $/ \mathrm{mL}$ and were subsequently treated with $2 \mu \mathrm{g} / 330$ $\mathrm{mL}$ of free uncoated AgNP, PB-Lipo-AgNP or Ex-Lipo- 331 AgNP for $24 \mathrm{~h}$. As a positive kill control, THP1 cells 331 exposed to $10 \%$ DMSO was also incorporated. After nano- 333 particle exposure, the cells were harvested into $15 \mathrm{~mL}$ tubes 334 and were centrifuged at $300 \times \mathrm{g}$ for $5 \mathrm{~min}$ at $21^{\circ} \mathrm{C}$. The 335 supernatant was discarded while the pellets were resus- 336 pended and rinsed twice in $2 \mathrm{~mL}$ prewarmed $1 \times \mathrm{PBS}$ and 337 centrifuged. The cells were then resuspended in $1 \mathrm{~mL}$ bind- 338 ing buffer containing $0.1 \% \mathrm{NaN}_{3}$ and $1 \%$ bovine serum 339 albumin (BSA) solution in $1 \times$ PBS. The cells were double 340 stained with $5 \mu \mathrm{L}$ of $1 \mu \mathrm{M}$ calcein-AM stain and $10 \mu \mathrm{L}$ of 341 $10 \mu \mathrm{g} / \mathrm{mL}$ PI and incubated in the dark at RT for $30 \mathrm{~min} 342$ and analyzed with a BD Accuri C6 flow cytometer.

\subsection{Confocal microscopy}

THP1 cells were seeded onto a confocal dish (VWR, Dublin 347 Ireland) at density of $3 \times 10^{5}$ cells $/ \mathrm{mL}$. The cells were also 348 stimulated with $100 \mathrm{ng} / \mathrm{mL}$ of PMA for $24 \mathrm{~h}$ and subsequently 349 treated with RPMI media containing $2 \mu \mathrm{g} / \mathrm{mL}$ of either PB- 350 
Table 1. Size and Zeta potential of uncoated AgNP, PB-Lipo-AgNP and Ex-Lipo-AgNP in ddH $\mathrm{O}_{2} \mathrm{O}$ and RPMI-1640.

\begin{tabular}{|c|c|c|c|c|}
\hline & \multicolumn{2}{|c|}{$\mathrm{ddH}_{2} \mathrm{O}$} & \multicolumn{2}{|c|}{ media } \\
\hline & Peak 1 (\%) & Peak 2 (\%) & Peak 1 (\%) & Peak 2 (\%) \\
\hline \multicolumn{5}{|l|}{ Uncoated AgNP } \\
\hline DLS Intensity PSD (nm) & $21.14 \pm 9.48$ & - & $79.15 \pm 66.67$ & - \\
\hline Zeta $(\mathrm{mV})$ & -26.50 & - & -7.90 & - \\
\hline PDI & 0.230 & - & 0.566 & - \\
\hline \multicolumn{5}{|l|}{ PB-Lipo-AgNP } \\
\hline DLS Intensity PSD (nm) & $143.7 \pm 64.18(98.7)$ & $5005 \pm 605.6(1.3)$ & $268.7 \pm 186.9(80.4)$ & $2555 \pm 1325$ (19.6) \\
\hline Zeta $(\mathrm{mV})$ & -25.9 & & -0.96 & \\
\hline PDI & 0.305 & & 0.437 & \\
\hline \multicolumn{5}{|l|}{ Ex-Lipo-AgNP } \\
\hline DLS Intensity PSD (nm) & $140.1 \pm 47.49(100)$ & $\mathrm{N} / \mathrm{A}$ & $138.9 \pm 54.93(86)$ & $3928 \pm 1081(14)$ \\
\hline Zeta $(\mathrm{mV})$ & -31.9 & & -0.61 & \\
\hline PDI & 0.105 & & 0.421 & \\
\hline
\end{tabular}

Lipo-AgNP and Ex-Lipo-AgNP for $24 \mathrm{~h}$. Dish containing cells exposed to $0.5 \mathrm{nM}$ doxorubicin were incorporated as positive kill control. After exposure, the media were discarded, and the cells were rinsed with pre-warmed sterile PBS. The cells were stained with $50 \mu \mathrm{L}$ of $1 \mu \mathrm{M}$ calcein-AM and $50 \mu \mathrm{L}$ of $10 \mu \mathrm{g} /$ $\mathrm{mL}$ PI. The cells were then incubated in the dark at RT for $20 \mathrm{~min}$ and rinsed with warm PBS afterwards. Prior to imaging, $1 \mathrm{~mL}$ of warm PBS was added onto the cells and imaging was carried out with Zeiss LSM 510 Confocal Laser Scanning Microscope using a Plan-Neofluor oil immersion lens at $40 \times$ magnification and 1.3 numerical aperture.

\subsection{Statistical analysis}

Statistical analysis was carried out using GraphPad Prism version 7. Data was analyzed by Two-way analysis of variance (ANOVA) with Sidak or Turkey multiple comparisons test to detect significance. Statistically significant differences in tests were indicated for $p$ value $<0.05$.

\section{Results}

\subsection{DLS characterization}

Results of the DLS characterization of AgNP is summarized in Table 1 for dispersions in water $\left(\mathrm{ddH}_{2} \mathrm{O}\right)$ and RPMI-1640 culture media. DLS analysis of AgNP shows an increase in mean particle size (MPS) of AgNP when dispersed in $\mathrm{ddH}_{2} \mathrm{O}$ to RPMI-1640 media from $21.14 \mathrm{~nm}$ to $79.15 \mathrm{~nm}$ with polydispersity index (PDI) $0.230-0.566$ respectively. The zeta analysis for AgNP in $\mathrm{ddH}_{2} \mathrm{O}$ was $-26.5 \mathrm{mV}$ which dropped to $-7.90 \mathrm{mV}$ in RPMI-1640 media. There was also change in AgNP color from golden yellow in $\mathrm{ddH}_{2} \mathrm{O}$ to dark gray when dispersed in RPMI-1640 media which is likely due to agglomeration of the nanoparticle.

\subsection{SEM/STEM and spectra analysis of AgNP}

SEM analysis of the AgNP showed a spherical nanoparticle with average size of $14.3 \pm 1.9 \mathrm{~nm}$ (Figure 1A). The UV-Vis spectra of the different AgNP concentration ranging from 0.625 to $10 \mu \mathrm{g} / \mathrm{mL}$ are depicted in Figure 1B, showing a characteristic peak absorption $(\lambda \max )$ corresponding to the surface plasmon resonance (SPR) of $20 \mathrm{~nm} \mathrm{AgNP}$ at around

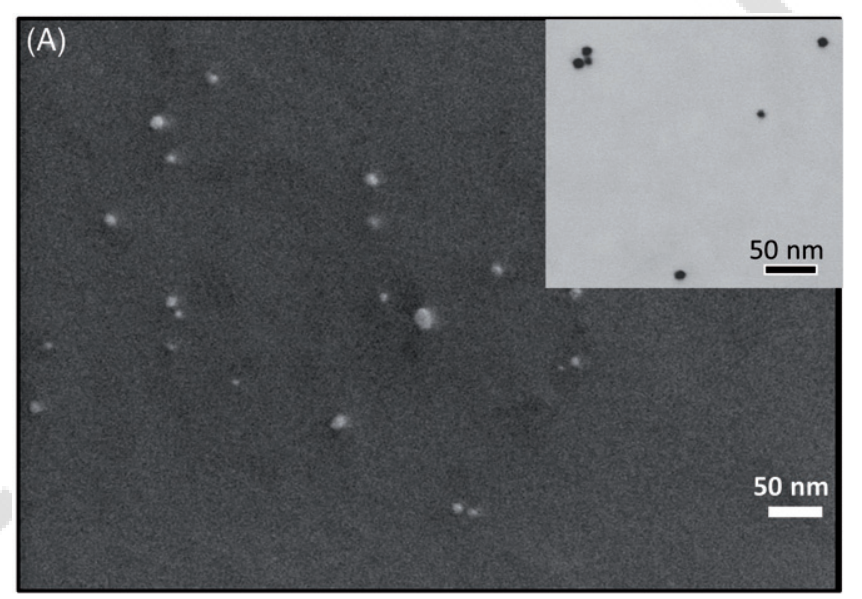

424

425

COLOQ25 B\&W427

Print 428

429

430

431

432

433

434

435

436

437

438

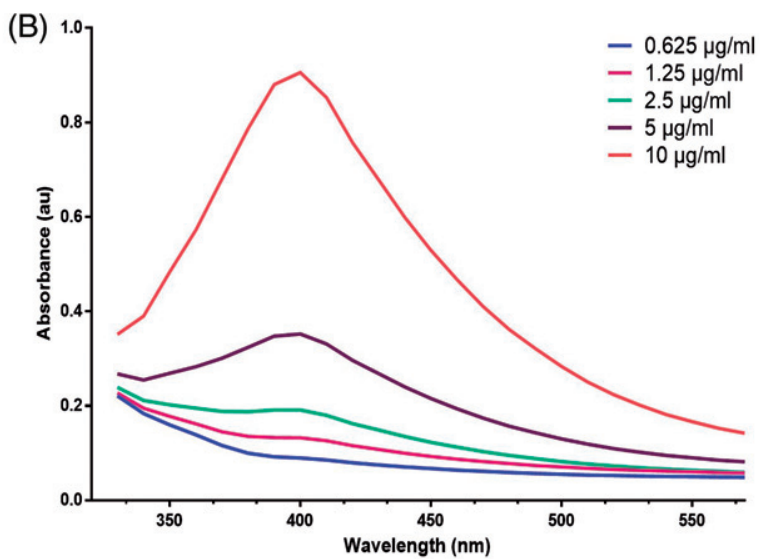

Figure 1. SEM/STEM and UV-Vis Spectra analysis of AgNP (A) SEM and of AgNP with STEM image inset (B) UV spectra analysis of $0.625-10 \mu \mathrm{g} / \mathrm{mL}$ of AgNP measured at $22.6^{\circ} \mathrm{C}$.

$400 \mathrm{~nm}$, which was the approximate size obtained by DLS. The peak flattening corresponds to decrease in concentration of AgNP, explained by the reduction in the amount of AgNP particles that absorbs UV light at the wavelengths indicated.

\subsection{Liposome characterization}

PB-Lipo-AgNP size increased from 143.7 when in $\mathrm{ddH}_{2} \mathrm{O}$ to $268.7 \mathrm{~nm}$ after dispersion in RPMI-1640 media (Table 1). A second peak of larger sized particles was observed in both ddH2O (1.3\%) and RPMI media (19.6\%) likely due to agglomeration. The PDI of PB-Lipo-AgNP also increased
439

440

441

442

443

444

445

446

447

448

449

450

451

452

453

454

455

456

457

458

459

460

461

462

463

464

465

466

467

468 
from 0.305 to 0.437 after resuspension in RPMI-1640 media but there was a reduction in zeta potential from $-25.9 \mathrm{mV}$ in $\mathrm{ddH}_{2} \mathrm{O}$ to -0.96 after dispersion in RPMI-1640 media.

For Ex-Lipo-AgNP, there was a small decrease in size from $140.1 \mathrm{~nm}$ in $\mathrm{ddH}_{2} \mathrm{O}$ to $138.9 \mathrm{~nm}$ (half that of PB-LipoAgNP) when dispersed in RPMI-1640 media. Unlike the PB-Lipo-AgNP, extrusion produced Lipo-AgNP that was $100 \%$ uniform in size in $\mathrm{ddH}_{2} \mathrm{O}$, however, a second peak was found at $3.9 \mu \mathrm{m}$ for $14 \%$ of the particles in RPMI media (Table 1). In contrast, Ex-Lipo-AgNP had a PDI of 0.105 in $\mathrm{ddH}_{2} \mathrm{O}$ but this increased to 0.421 in RPMI-1640 media. There was also a reduction in zeta potential of Ex-LipoAgNP from $-31.9 \mathrm{mV}$ in $\mathrm{ddH}_{2} \mathrm{O}$, higher than that of $\mathrm{PB}$ Lipo-AgNP to $-0.61 \mathrm{mV}$ in RPMI-1640.

An overlay of DLS size values of the uncoated AgNP in $\mathrm{ddH}_{2} \mathrm{O}$ was carried out with the size values of the PB-LipoAgNP obtained with the same AgNP solution both in $\mathrm{ddH}_{2} \mathrm{O}$ and in RPMI media (Figure 2C). Overlap in AgNP size value with that of the PB-Lipo-AgNP dispersed in $\mathrm{ddH}_{2} \mathrm{O}$ was observed, indicating some of AgNP had not been encapsulated within the PB-Lipo-AgNP. In addition, a shift in the major peak of the PB-Lipo-AgNP was observed for a $120 \mathrm{~nm}$ increase in size from dispersion in $\mathrm{ddH}_{2} \mathrm{O}$ to RPMI, accounting for $20 \%$ of the total nanoparticle. Ex-Lipo-AgNP exhibited no overlap with AgNP in both dispersion media, indicating both nanoparticles have distinct populations (Figure 2D). In addition, there was only a single peak observed for Ex-Lipo-AgNP dispersed in $\mathrm{ddH}_{2} \mathrm{O}$ indicative of uniform nanoparticle although there was a slight shift in the major peak to the left as the size reduced by $1.2 \mathrm{~nm}$ while a second peak was also visible, accounting for
$14 \%$ of the total nanoparticle likely due to agglomeration 528 in RPMI.

\subsection{UV-Vis spectra analysis of encapsulated AgNP and encapsulation efficiency}

Different concentrations of PB-Lipo-AgNP and extruded 535 AgNP, were analyzed by UV-Vis spectra to investigate 536 whether the AgNP has been successfully encapsulated 537 (Figures 3A and 3B). PB-Lipo-AgNP showed a similar spec- 538 tra characteristic with AgNP especially at $10 \mu \mathrm{g} / \mathrm{mL}$ but there 539 was a red shift in the AgNP peak at around $410 \mathrm{~nm}$, observ- 540 able for both $5 \mu \mathrm{g} / \mathrm{mL}$ and $10 \mu \mathrm{g} / \mathrm{mL}$. There was consider- 541 able peak flattening at concentration $\leq 5 \mu \mathrm{g} / \mathrm{mL}$ (Figure 3A). 542 It was observed that PB-Lipo-AgNP was cloudy with lipids 543 and retained the golden yellow color of AgNP showing pres- 544 ence of free AgNP (Figure 2A inset). On the contrary for 545 Ex-Lipo-AgNP, the peak absorbance was barely observed 546 even at $10 \mu \mathrm{g} / \mathrm{mL}$ and there was also a red shift in the peak 547 at around $410 \mathrm{~nm}$ (Figure 3B). Ex-Lipo-AgNP solution was 548 clear and did not retain the golden yellow color of AgNP 549 (Figure 2B inset), likely because of the refraction due to the 550 lipid layer of the liposome. PB-Lipo-AgNP also had higher 551 absorbance compared to Ex-Lipo-AgNP (at $10 \mu \mathrm{g} / \mathrm{mL}$ ) which 552 has similar baseline with uncoated AgNP (Figure 3C), indi- 553 cating no agglomeration of Ex-Lipo-AgNP. The EE was 555 determined to be $67.8 \%$ and $86.5 \%$ for the PB-Lipo-AgNP 556 and Ex-Lipo-AgNP respectively, which may explain the sim- 557 ilarities between the UV-Vis spectra of free AgNP and PB- 558 Lipo-AgNP since less AgNP was encapsulated.

\section{9}

560

561

562

563

564

565

566

567

568

569

570

571

572

573

574

575

576

577

578

579

580

581

582

583

584

Size $(\mathrm{nm})$ Figure 2. SEM/STEM of PB-Lipo-AgNP and Ex-Lipo-AgNP: (A) SEM with STEM (inset) of PB-Lipo-AgNP, and overlay of AgNP size value with PB-Lipo-AgNP (B) SEM 585
with STEM (inset) Ex-Lipo-AgNP and overlay of AgNP size value with Ex-Lipo-AgNP.
586 

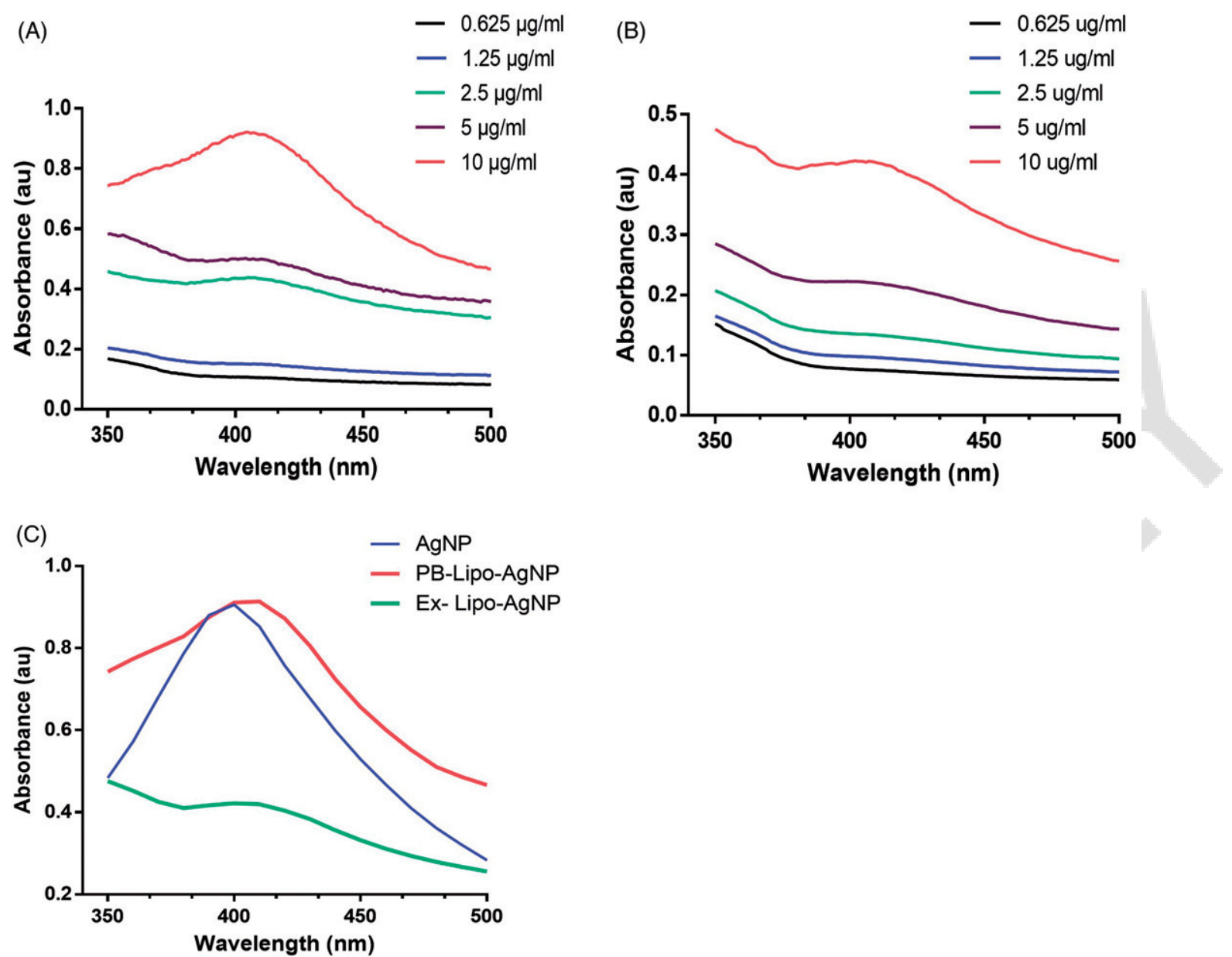

Figure 3. UV-Vis Spectra of PB-Lipo-AgNP and Ex-Lipo-AgNP: UV-Vis spectral analysis of(A) PB-Lipo-AgNP and (B) Ex-Lipo-AgNP at different concentrations between $0.625 \mu \mathrm{g} / \mathrm{mL}$ and $10 \mu \mathrm{g} / \mathrm{mL}$ (C) combined UV-Vis spectra of $10 \mu \mathrm{g} / \mathrm{mL}$ AgNP, Ex-Lipo-AgNP and PB-Lipo-AgNP.

\subsection{SEM/STEM analyses of Lipo-AgNP}

PB-Lipo-AgNP and Ex-Lipo-AgNP were analyzed microscopically by SEM and STEM (Figures $2 \mathrm{~A}$ and $2 \mathrm{~B}$ ). As shown, PB-Lipo-AgNP formed agglomerates unlike Ex-LipoAgNP. SEM analysis of Ex-Lipo-AgNP showed nonagglomerating spherical liposomes with a well-defined structure. STEM of the PB-Lipo-AgNP (Figure 2A inset) showed AgNP found coated on the liposome with very few nanoparticles encapsulated within. The AgNP in Ex-Lipo-AgNP shown in the STEM (Figure 2B inset) were all encapsulated within the liposome (gray sphere). This alludes to the EE and spectra characteristics of both PB-Lipo-AgNP and ExLipo-AgNP. Size estimation from SEM indicated Ex-LipoAgNP was $162.73 \pm 29.23 \mathrm{~nm}$ while the PB-Lipo-AgNP was $204.22 \pm 45.39 \mathrm{~nm}$ representing the average of 20 particles counted and similar to the value obtained by DLS.

\subsection{Temperature-dependent size change, stability analyses and load release profile of Lipo-AgNP}

The practicability of the Lipo-AgNP to retain their contents in in vitro experiments was tested under incubation conditions. Sizes of both PB-Lipo-AgNP and Ex-Lipo-AgNP with respect to temperature changes was monitored using DLS in RPMI1640 media containing $10 \%$ FBS over $6 \mathrm{~h}$ at $20 \mathrm{~min}$ interval for a degree rise in temperature. The initial size of PB-LipoAgNP doubled that of Ex-Lipo-AgNP confirming the values in Table 1. PB-Lipo-AgNP size reduced from $334 \mathrm{~nm}$ at $20^{\circ} \mathrm{C}$ to $150.2 \mathrm{~nm}$, a $55 \%$ reduction in size at $37^{\circ} \mathrm{C}$. For Ex-LipoAgNP, a reduction from $174.7 \mathrm{~nm}$ at $20^{\circ} \mathrm{C}$ to $113.1 \mathrm{~nm}$ at $37^{\circ} \mathrm{C}$, a $35.3 \%$ reduction in size was observed (Figure $4 \mathrm{~B}$ ). This reduction in size could be as result of loss of liposomal content due to increase in temperature.

Stability analyses of the liposomes over a 6-month period is shown in Table 2. After 6 months of incubation, the MPS and zeta potential of PB-Lipo-AgNP increased by $10.3 \mathrm{~nm}$ and $5.1 \mathrm{mV}$ respectively at $4^{\circ} \mathrm{C}$. Compared to $4{ }^{\circ} \mathrm{C}$, PB-Lipo-AgNP at $24^{\circ} \mathrm{C}$ exhibited a higher reduction in MPS and zeta potential of $19 \mathrm{~nm}$ and $4.3 \mathrm{mV}$ for the 6 months in addition to the sedimentation of the lipids that was observed. On the contrary, Ex-Lipo-AgNP showed slight increase in size as well as zeta potential over the 6-month period. At $4{ }^{\circ} \mathrm{C}$, an overall $3.2 \mathrm{~nm}$ and $2.0 \mathrm{mV}$ MPS and zeta potential was observed, which was comparable to that observed at $24^{\circ} \mathrm{C}(5.9 \mathrm{~nm}$ and $2.5 \mathrm{mV}$ MPS and zeta potential respectively), and lower to that of PB-Lipo-AgNP for the same time points.

The load release profile of both Lipo-AgNPs was carried out to evaluate AgNP release from the nanocapsule using dialysis. Due to the large volume of fluid outside the dialysis tube and the effect this will have on the absorbance of minute quantity of released nanoparticles from the dialysis 
tube, the absorbance of the sample inside of the dialysis tube was measure instead, as drop in absorbance will corresponds to the amount of AgNP released into the buffer. As shown in Figure 5A, PB-Lipo-AgNP appeared to have initial burst release of AgNP as more than $25 \%$ of the encapsulated AgNP was released within the first $2 \mathrm{~h}$ at $\mathrm{pH} 6.5$. Afterwards, a release of $29 \%$ to $30 \%$ at 4 and $6 \mathrm{~h}$ respectively was observed. Unlike PB-Lipo-AgNP, the extruded AgNP showed a steady release from $2 \mathrm{~h}$ up till $6 \mathrm{~h}$, releasing only $15 \%$ of the encapsulated AgNP at $6 \mathrm{~h}$, a significantly lower release to that of PB-Lipo-AgNP. Both nanocapsules exhibited similar release at $24 \mathrm{~h}$ with PB-Lipo-AgNP releasing $80 \%$ of encapsulated AgNP while Ex-Lipo-AgNP released $74 \%$. At physiological $\mathrm{pH}$ of 7.45, PB-Lipo-AgNP exhibited lower release rate of AgNP from $2 \mathrm{~h}$ to $6 \mathrm{~h}$ releasing $0.8 \%$ to $12.5 \%$ respectively. In the same time point,
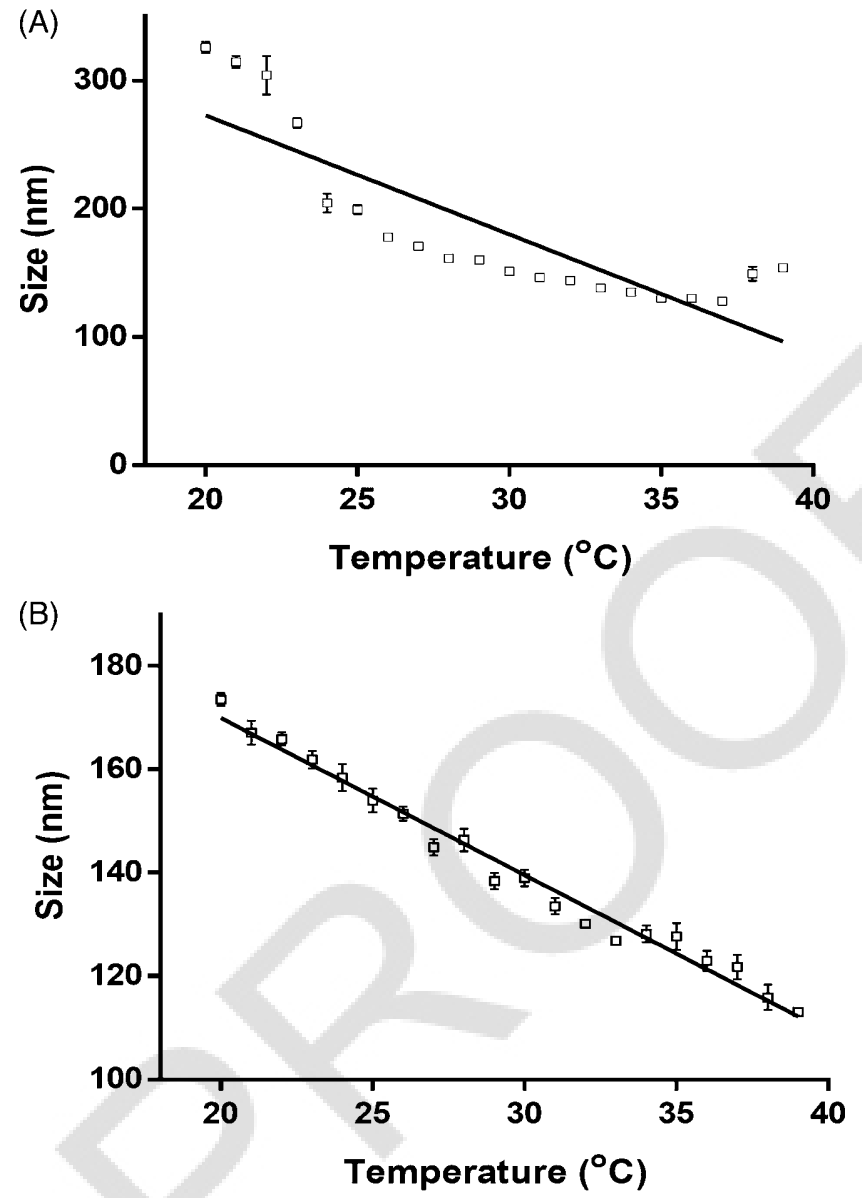

Figure 4. Stability kinetics of probe-sonicated and Ex-Lipo-AgNP: Temperature dependent changes in the sizes of (A) PB-Lipo-AgNP and (B) Ex-Lipo-AgNP dispersed in RPMI-1640 culture medium were analyzed by DLS. Values are mean \pm SD from average of three independent measurements.
Ex-Lipo-AgNP only released $0.7 \%$ to $3.5 \%$ respectively, a 764 significantly lower release than that of PB-Lipo-AgNP. At 765 $24 \mathrm{~h}$, Ex-Lipo-AgNP released 70\%, a significantly lower 766 release compared with PB-Lipo-AgNP exhibiting 79\% 767 AgNP release (Figure 5B).

\subsection{Cell viability}

To evaluate if the stability of Ex-Lipo-AgNP translates to 772 enhanced cytotoxicity, THP1 cells were first stimulated with 773 $100 \mathrm{ng} / \mathrm{mL}$ PMA to induce adherence of the cell line prior to 774 exposure to facilitate easy removal of uninternalized lipo- 775 some and prevent cell loss during wash steps. After $24 \mathrm{~h}$ of 776 exposure to the nanoparticles, viability of the PMA-stimu- 777 lated THP1 cells was evaluated by their ability to convert 779 the non-fluorescent resazurin in $\mathrm{AB}$ dye into a fluorescent 780 resorufin. As shown in Figure 6A, Ex-Lipo-AgNP induced 781 significant reduction in cell viability at concentration $\geq 1.25782$ $\mu \mathrm{g} / \mathrm{mL}$ while uncoated AgNP and PB-Lipo-AgNP induced 783
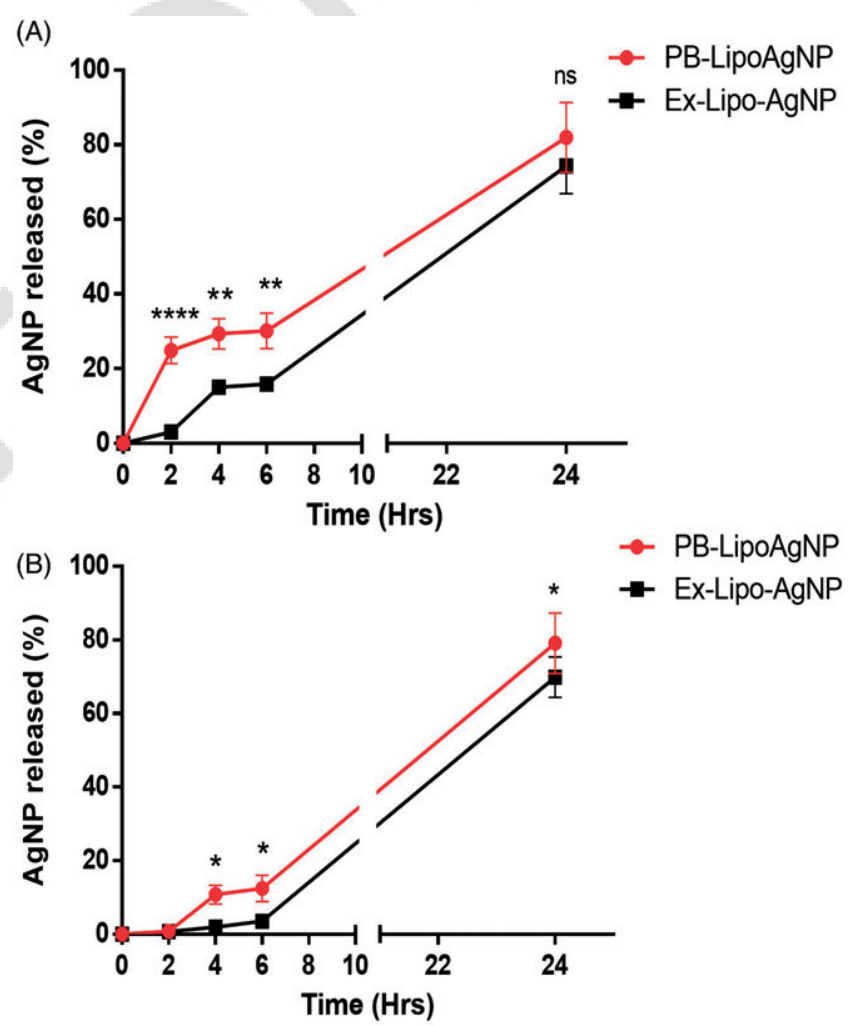

PB-LipoAgNP Ex-Lipo-AgNP

Figure 5. $\mathrm{pH}$ dependent drug release profile of PB-Lipo-AgNP and Ex-LipoAgNP: Encapsulated AgNP in (A) acetate buffer at pH 6.5 or (B) PBS at pH 7.45 and at specific time interval, $200 \mu \mathrm{L}$ of the sample was taken out for absorbance measurement. Data is presented as mean \pm SD of 3 independent experiments ${ }^{*} p<0.05,{ }^{* *} p<0.01, * * * * p<0.0001$.

Table 2. Stability of PB-Lipo-AgNP and Ex-Lipo-AgNP over a 6-month period.

\begin{tabular}{|c|c|c|c|c|c|c|c|c|}
\hline \multirow[b]{2}{*}{ Temp } & \multirow[b]{2}{*}{ Initial size $(\mathrm{nm})$} & \multirow[b]{2}{*}{ Initial Zeta $(\mathrm{mV})$} & \multicolumn{2}{|c|}{ Month 1} & \multicolumn{2}{|c|}{ Month 3} & \multicolumn{2}{|c|}{ Month 6} \\
\hline & & & Size $(\mathrm{nm})$ & Zeta $(\mathrm{mV})$ & Size $(\mathrm{nm})$ & Zeta $(\mathrm{mV})$ & Size $(\mathrm{nm})$ & Zeta $(\mathrm{mV})$ \\
\hline $\begin{array}{l}\text { PB-Lipo-AgNP } \\
4^{\circ} \mathrm{C} \\
24^{\circ} \mathrm{C}\end{array}$ & $143.7 \pm 64.18$ & -25.9 & $\begin{array}{l}149.44 \pm 9.7 \\
153.27 \pm 9.61\end{array}$ & $\begin{array}{l}-25.5 \\
-24.1\end{array}$ & $\begin{array}{c}151 \pm 13.3 \\
156.26 \pm 8.9\end{array}$ & $\begin{array}{l}-24.3 \\
-23.1\end{array}$ & $\begin{array}{c}154 \pm 20.3 \\
161.34 \pm 14.5\end{array}$ & $\begin{array}{l}-20.8 \\
-19.6\end{array}$ \\
\hline $\begin{array}{l}\text { Ex-Lipo-AgNP } \\
4^{\circ} \mathrm{C} \\
24^{\circ} \mathrm{C}\end{array}$ & $140.1 \pm 47.49$ & -31.9 & $\begin{array}{l}142.23 \pm 3.4 \\
141.33 \pm 1.72\end{array}$ & $\begin{array}{l}-30.5 \\
-30.9\end{array}$ & $\begin{array}{l}144.4 \pm 2.5 \\
145 \pm 1.98\end{array}$ & $\begin{array}{l}-30.0 \\
-30.7\end{array}$ & $\begin{array}{c}143.33 \pm 1.3 \\
146 \pm 2.4\end{array}$ & $\begin{array}{l}-29.9 \\
-29.4\end{array}$ \\
\hline
\end{tabular}



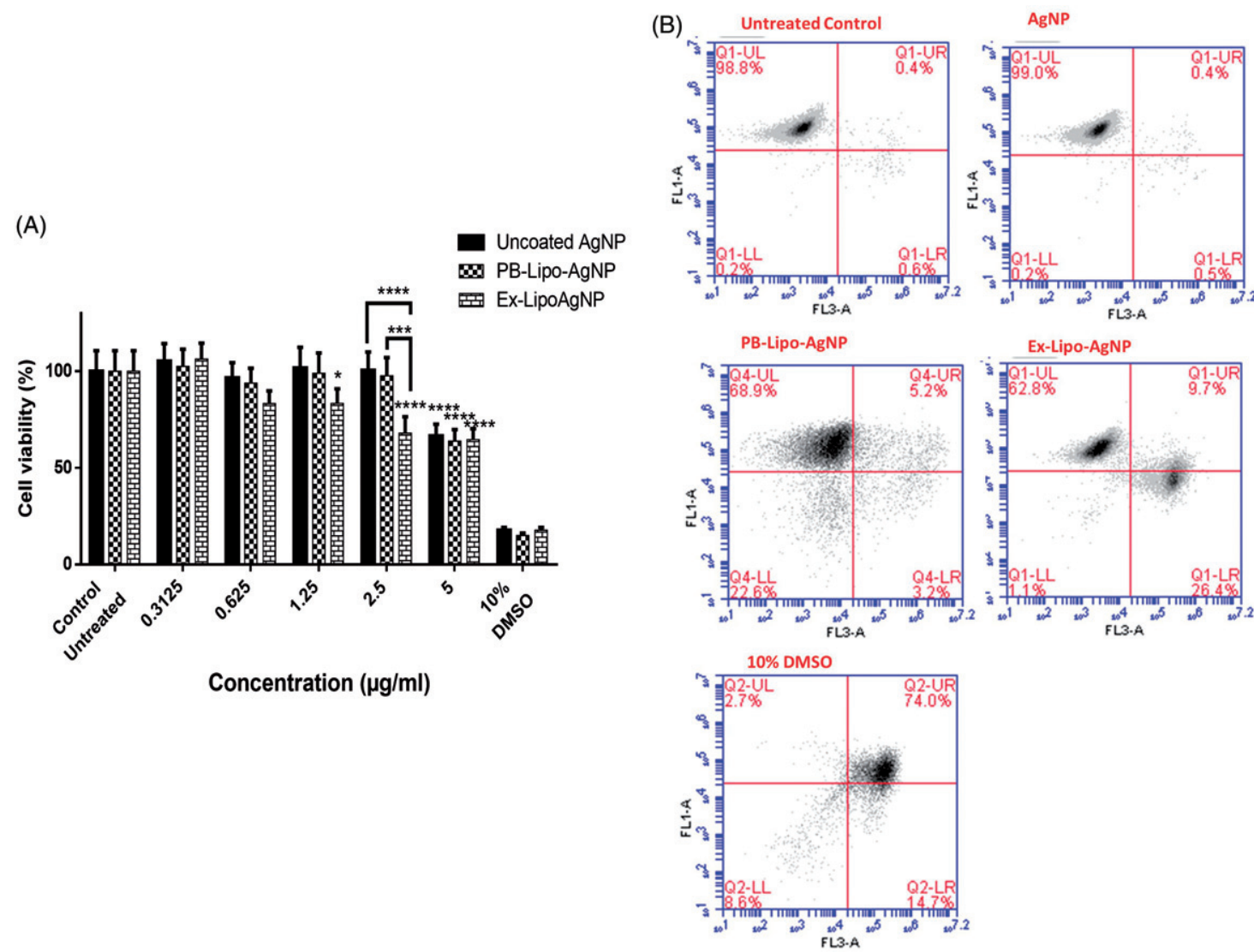

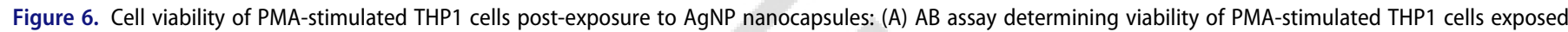

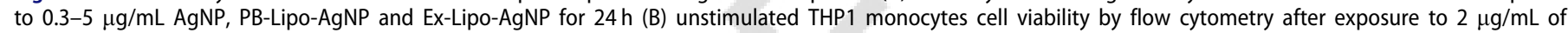

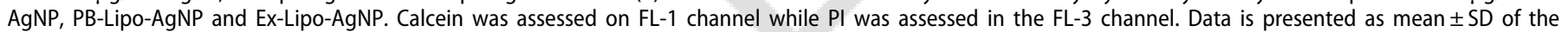
three independent experiments and similar values were obtained. $* * * p<0.001$ and $* * * * p<0.0001$.

significant reduction in the THP1 cell viability at $5 \mu \mathrm{g} / \mathrm{mL}$. It was observed that Ex-Lipo-AgNP at concentrations of 1.25 and $2.5 \mu \mathrm{g} / \mathrm{mL}$ were significantly more cytotoxic on THP1 cell than the PB-Lipo-AgNP at the same concentration.

A flow cytometry cell viability study was carried out to confirm $\mathrm{AB}$ finding since flow cytometry is a more accurate analyses of viability on a cell by cell basis. THP1 monocytes exposed to AgNP, PB-Lipo-AgNP and Ex-Lipo-AgNP were stained with calcein-AM and PI. Calcein-AM is a non-fluorescent stain hydrolyzed by esterase activity of viable cell into a fluorescent calcein derivative that is maintained within cell with intact cell membrane ${ }^{[12]}$, while PI only permeates compromised membrane of dead cells. As expected, Ex-LipoAgNP induced significantly more cell death compared to free AgNP and PB-Lipo-AgNP $(p<0.001)$. A significantly higher proportion of early apoptotic cells positive for both calcein and PI (9.7\%) and late apoptotic cells that are only positive for PI (26.4\%) was observed in Ex-Lipo-AgNP exposed cells compared to unexposed control cells, free AgNP and PB-Lipo-AgNP exposed groups (Figure 6B). In addition to this, PB-Lipo-AgNP exposure resulted in higher proportion of cells identified as cellular debris (22.6\%) compared to Ex-Lipo-AgNP (1.1\%) which was similar to that in untreated controls and free AgNP exposed cells (0.2\%) $(p<0.001)$. This cell population are likely due to PB-LipoAgNP identified as cellular debris due to the larger and ununiform sizes.
To further confirm the effect of the Lipo-AgNPs on cell viability, confocal microscopy was used to analyze calceinAM and PI stained PMA-stimulated THP1 cells exposed to nanocapsules containing equivalent amount of $2 \mu \mathrm{g} / \mathrm{mL}$ AgNP for $24 \mathrm{~h}$. THP1 cells that were exposed to either of PB-Lipo-AgNP or Ex-Lipo-AgNP appeared to have spotted calcein fluorescence (Figures 7A and 7B). This was unlike the control-untreated THP1 cells which appeared to have uniform calcein stain throughout the cytoplasm. In addition, only Ex-Lipo-AgNP induced significantly higher cytotoxicity on THP1 cells compared with control-untreated or PBLipo-AgNP exposed cells $(p<0.01)$ (Figures $7 \mathrm{~A}$ and $7 \mathrm{~B}$ ). Similarly, only Ex-Lipo-AgNP resulted in significantly higher PI fluorescence when compared to both PB-Lipo-AgNP exposed and control-untreated cells $(p<0.001)$. Thus, verifying the result of the $\mathrm{AB}$ and flow cytometry assays.

\section{Discussion}

AgNP can be synthesized from $\mathrm{AgNO}_{3}$ by different methods such as using reducing agents like citrate or $\mathrm{NaBH}_{4}$ with further stabilization of the nanoparticle with compounds such as polyvinyl alcohol (PVA) ${ }^{[13-15]}$. A citrate-based reduction is most commonly used in the synthesis of AgNP because of its reducing and stabilizing functionality. However, reduction of $\mathrm{AgNO}_{3}$ with citrate results in formation of AgNP in complex with the citrate ions which prevents the release of elemental 
(A)

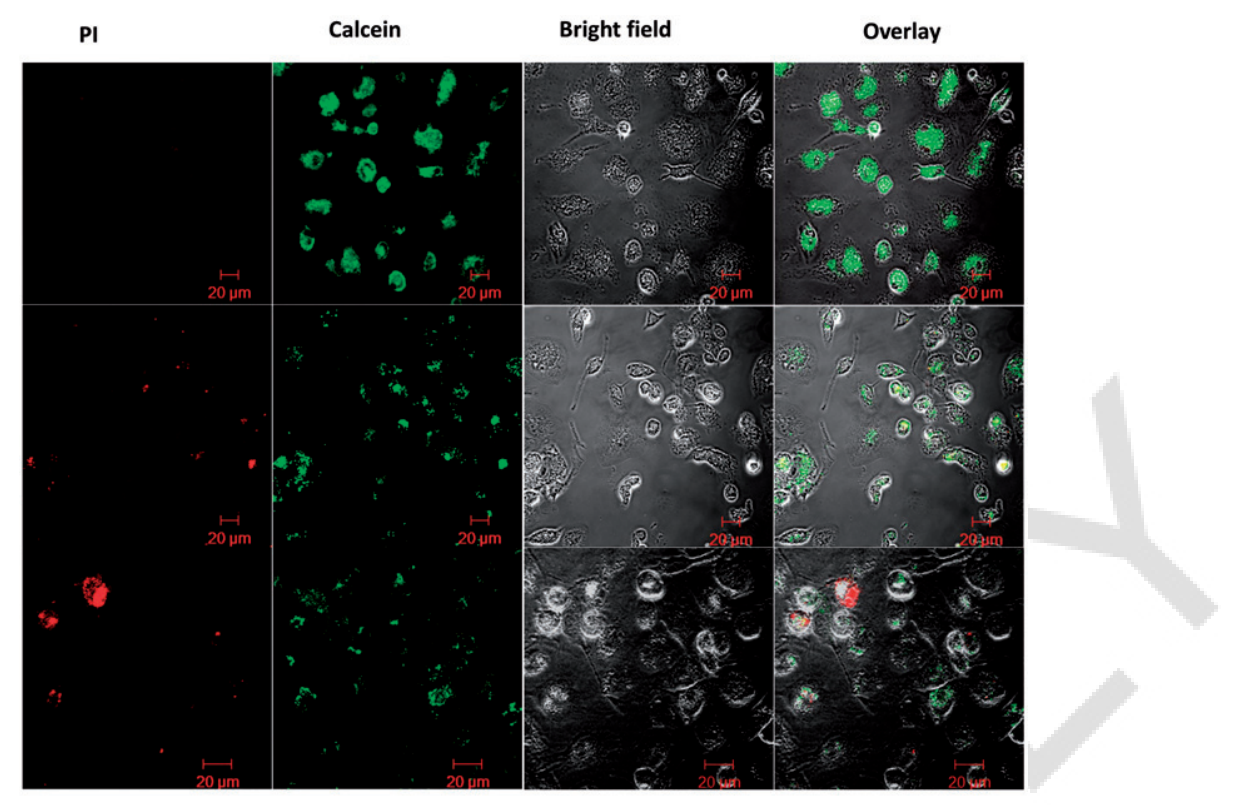

(B)

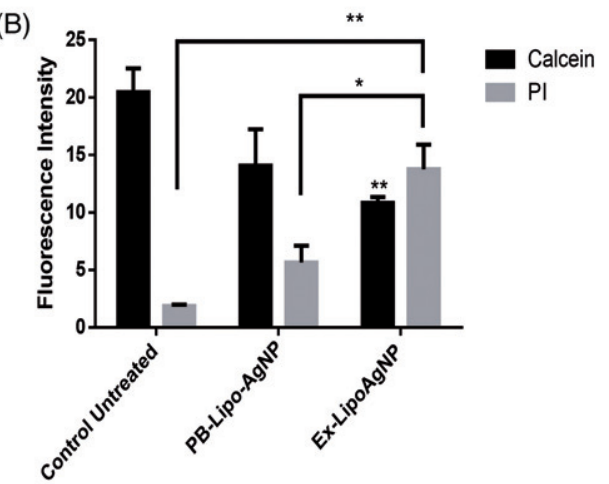

1000

1001

1002

1003

1004

1005

1006

1007

1008

1009

1010

1011

1012

1013

1014

1015

1016

1017

1018

1019

1020

1021

1022

1023

1024

1025

1026

1027

1028

1029

1030

1031

1032

1033

1034

1035 believed that PB-Lipo-AgNP increased size could have significant impact on cellular response. It is known that larger nanoparticles have reduced bioavailability as they are quickly eradicated by the reticulo-endothelial system ${ }^{[17]}$, making PB-Lipo-AgNP less practical for in vitro applications as a drug delivery system. PB-Lipo-AgNP exhibited a lower zeta 1036 1037 1038 1039 1040 1041 1042 1043 1044 1045 1046 1047 1048 1049 1050 1051 1052 1053 $-31.9 \mathrm{mV}$. Nanoparticles with zeta potential value between -30 and $+30 \mathrm{mV}$ are considered less stable owing to the between the particles ${ }^{[18]}$, indicating the Ex-Lipo-AgNP is more stable. In addition to this, the PDI of PB-Lipo-AgNP was found to be higher than that of Ex-Lipo-AgNP in $\mathrm{ddH}_{2} \mathrm{O}$, indicating that Ex-Lipo-Ag
size compared to PB-Lipo-AgNP.

The UV-Vis spectra analysis of free AgNP conformed with reported SPR characteristic of a $20 \mathrm{~nm}$ AgNP which is at $400 \mathrm{~nm}{ }^{[19]}$, in a way confirming the DLS size of $21 \mathrm{~nm}$. $\mathrm{UV}-\mathrm{Vis}$ spectra analysis of both PB-Lipo-AgNP and ExLipo-AgNP also allude the success of the encapsulation process. PB-Lipo-AgNP and AgNP had a similar spectra profile with same $\lambda$ max although PB-Lipo-AgNP spectra exhibited a broadened peak with a raised baseline and a red shift in the $\lambda \max$, which are indicative of agglomeration/size successfully encapsulated absorbing UV emission to produce 1055 the observed spectrum. In support of this, an overlap in the 1056 DLS size value of AgNP with the $\mathrm{ddH}_{2} \mathrm{O}$ dispersed PB-Lipo- 1057 AgNP observed indicates that the PB-Lipo-AgNP particles in 1058 increase. The $\lambda \max$ also indicates free AgNP that are not 1054 
the overlap region is more likely to be uncoated AgNP. Contrastingly, Ex-Lipo-AgNP spectra depicted a flat peak with same baseline as free AgNP which hints at nonagglomeration of the nanoparticle. The spectra observed at $10 \mu \mathrm{g} / \mathrm{mL}$ was similar to that of $1.25 \mu \mathrm{g} / \mathrm{mL}$ of free AgNP indicating less free AgNP that are able to absorb at the UVVis wavelength. This observation is also supported by nonoverlap of the AgNP and Ex-Lipo-AgNP DLS size values.

Interaction between nanoparticles and culture media proteins is not uncommon based on their surface reactivity. This interaction was monitored through the size and zeta potential of the liposomes in RPMI-1640 medium. There was increase in the size of PB-Lipo-AgNP and drastic reduction in its zeta potential. The dramatic increase in PB-LipoAgNP size in RPMI-1640 could be due to the AgNP on the surface interacting with the proteins in the culture medium as also observed for free AgNP. This is in agreement with the findings of Sabuncu et al. ${ }^{[20]}$ who also reported an increase in gold nanoparticle size and decrease in the zeta potential when dispersed in fetal calf serum (FCS) supplemented DMEM culture. This is supported by the DLS overlay of PB-Lipo-AgNP in $\mathrm{ddH}_{2} \mathrm{O}$ and RPMI which indicates increase in size of the nanoparticle from dispersion in $\mathrm{ddH}_{2} \mathrm{O}$ to RPMI medium. On the contrary, there was a considerable drop in the zeta potential of Ex-Lipo-AgNP, with only a small increase in the percentage of nanoparticles with increased size (14\%). This could mean that Ex-Lipo-AgNP do not readily react with proteins in the culture medium, resulting in no net increase in the size after dispersion in FBS containing RPMI-1640 medium. Interestingly, the charges on the protein amino acids may have a masking effect on Ex-Lipo-AgNP zeta potential. The spectra characteristic of Ex-Lipo-AgNP was less similar to that of AgNP, although with a red shift in $\lambda \mathrm{max}$ at $410 \mathrm{~nm}$. Taken together with the similar baseline as free AgNP and the low absorbance at $\lambda \max$ which is about $50 \%$ less than that of free AgNP and PB-Lipo-AgNP, the shift is likely due to the increase in size contributed by the liposome. This also shows that the AgNP is bound to the liposome assuming a larger size than prior to encapsulation such that less AgNP particles are available to interact with proteins in the RPMI media and absorb UV emission. In a study investigating the use of AgNP as biosensor, a red shift in the spectra of a $19 \mathrm{~nm}$ AgNP was reported to be consequent upon the binding of the nanoparticle to protein ligands present on the biosensor platform ${ }^{[21]}$, explaining why there was no considerable change in the Lipo-AgNP size in the media.

In temperature dependent study, it was noted that the PB-Lipo-AgNP size decreased by more than half at $37^{\circ} \mathrm{C}$ whereas Ex-Lipo-AgNP only decreased in size by about a quarter of the original size. The reason for reduction in their sizes with increased temperature is not known, but this could be as a result of the increased fluidity of the lipid bilayer at temperature close to the transition temperature. Increased fluidity could result in the movement of the liposomal water content out of the liposome into the more concentrated culture medium by osmosis. A previous report indicated liposome often lose their aqueous content when dispersed in medium of high osmolarity ${ }^{[22]}$, such that water moves from region of lower concentration to region of higher concentration through the lipid bilayer. As such, ExLipo-AgNP appeared to be more stable with respect to its ability to retain its content at $37^{\circ} \mathrm{C}$. The stability study over a 6-months period also indicated Ex-Lipo-AgNP to be more stable with minimal overall increase in size and zeta potential at both $4{ }^{\circ} \mathrm{C}$ and $24^{\circ} \mathrm{C}$ compared to PB-Lipo-AgNP which was also found to sediment unlike the Ex-Lipo-AgNP that remained clear.

Encapsulation of AgNP in liposome here was carried out with the intent of improving its cytotoxicity as a chemotherapeutic agent. Hence, it became pertinent to carry out drug release studies. Considering the possible route of administration and target site for the encapsulated AgNP, $\mathrm{pH}$ of 7.45 which is the physiologic $\mathrm{pH}$ and most culture media (relevant for in vitro studies) and $\mathrm{pH} 6.5$ which is known to be the $\mathrm{pH}$ of the tumor microenvironment and inflamed tissue ${ }^{[23-25]}$, were considered. One of the major problems associated with drug delivery systems is the initial burst release which is associated with an initial hypertoxicity and suboptimal concentration of the drug at the time it reaches the target. A good drug delivery system is expected to protect the drug against the harsh physiological environment of immune cells, minimize the burst release and maintain a steady release of the drug for optimal concentration to achieve maximum efficacy over a period. Findings in this study, showed that PB-Lipo-AgNP possesses initial burst release at $\mathrm{pH} 6.5$ and 7.45. Ex-LipoAgNP exhibited and maintained a steady release of AgNP at $\mathrm{pH} 6.5$ with significantly lower release compared to $\mathrm{PB}$ Lipo-AgNP. At $24 \mathrm{~h}$, the two systems have released similar concentration of AgNP. At physiologic $\mathrm{pH}$ of 7.45, PBLipo-AgNP had already released $12.5 \%$ of the encapsulated AgNP compared to $3.5 \%$ of Ex-Lipo-AgNP. Initial burst release has been demonstrated for $\mathrm{Ag}^{+}$coated with titanium dioxide used as an antibacterial for Staphylococcus aureus $^{[26]}$. Although it was found that this rapid release produced an effective antibacterial effect, this effect can be quite adverse in an in vivo model.

Initial burst release has been proposed to occur consequent upon rapid dissolution of weakly or poorly encapsulated drugs that might be attached to the surface of the delivery systems ${ }^{[27-30]}$. This supports our deduction from $\mathrm{UV} / \mathrm{V}$ is spectra features of PB-Lipo-AgNP to weakly encapsulate AgNP with some free AgNP attached to the surface of the liposome as also depicted in the STEM image. Contrastingly, our finding indicated that Ex-Lipo-AgNP can maintain steady AgNP release at both $\mathrm{pH} 6.5$ and 7.45. The advantage is that the absence of initial burst release of Ex-Lipo-AgNP prevents initial hypertoxicity. On the other hand, while Ex-Lipo-AgNP had significantly less drug release at $24 \mathrm{~h}$ compared with PB-Lipo-AgNP at $\mathrm{pH} 7.45$, stability of Ex-Lipo-AgNP may facilitate better drug delivery with better net cytotoxicity. In support of the finding for Ex-Lipo-AgNP however, Ruttala and Ko ${ }^{[31]}$, showed that a liposomal anti-tumor agent with steady load release exhibited enhanced cytotoxicity. 
The uncertainty that encapsulation of AgNP translates to enhanced and improved cytotoxicity led to the investigation of the cytotoxicity of PB-Lipo-AgNP and Ex-Lipo-AgNP on THP1, a leukemic cell line in the monocytic lineage. The choice of the cell line for this study is three-folds. Firstly, THP1 is a leukemic (cancer) cell line, allowing investigation of the cytotoxic effect of AgNP encapsulation on a cancer cell line. Secondly, monocytes and similar immune cells act as first line of Defense in response to foreign objects including nanoparticles upon human exposure ${ }^{[32-34]}$, making the cell line a perfect model to also study the effect of the nanoparticle on the innate immune system. In addition to this, due to the role of monocytes in diseases such as atherosclerosis and cancer ${ }^{[35]}$, this cell line is a potential therapeutic target in treatment of this diseases.

Upon exposure of THP1 monocytes to the different nanoparticles, it was discovered that Ex-Lipo-AgNP induced significantly higher cytotoxicity at lower concentrations compared with PB-Lipo-AgNP and free uncoated AgNP exposed cells. In addition, flow cytometry and confocal microscopy analyses both confirmed Ex-Lipo-AgNP to be more cytotoxic compared to PB-Lipo-AgNP and free uncoated AgNP. There was a significantly higher live cells and less dead cells in the controluntreated, free uncoated AgNP, and PB-Lipo-AgNP exposed cells groups compared to Ex-Lipo-AgNP exposed cells. Another observation was the speckled fluorescence observed in both PB-Lipo-AgNP and Ex-Lipo-AgNP exposed cells but not the control-untreated cells. This is likely due to the loss of membrane integrity upon exposure to the nanoparticles resulting in leakage of calcein from the cytoplasm. Foged et al. ${ }^{[36]}$ have previously showed that disruption of the cell membrane can result in leakage of calcein.

The enhanced cytotoxicity of Ex-Lipo-AgNP in comparison to AgNP or PB-Lipo-AgNP may be attributed to its superior characteristics and enhanced delivery. This may have been facilitated by the hydrophobic interaction between the lipid bilayer of the cell membrane and that of the liposome encapsulating the AgNP. On the other hand, the slightly enhanced cytotoxicity of the PB-Lipo-AgNP may be because of less encapsulated AgNP and lower endocytosis due to larger size in culture media. This reason may also explain why Ex-Lipo-AgNP enhanced delivery into the cells since its size may have remained unchanged even when reconstituted in culture media. Lastly, flow cytometry detected more cellular debris in PB-Lipo-AgNP exposed THP1 cells than in other exposure groups. These debris were due to the PB-Lipo-AgNP which were larger in size and similar to left over of apoptosed cells. Unfortunately, this identified debris are counted as events in the cytometer, imposing a confounding effect on the number of viable cells that will be analyzed. Interestingly, Ex-Lipo-AgNP does not exhibit such anomaly, further alluding to the stability and superior characteristic liposome obtained through the extrusion as compared with that obtained from probe sonication. Taken together, encapsulation of AgNP in DPPC based liposome may help limit the concentration of AgNP used in the various biomedical applications to achieve better cytotoxicity resulting in less human exposure and mitiga- 1236 tion of any development of adverse effects.

\section{Conclusion} centration without the need for stabilizer. Synthesized AgNP 1242 were successfully encapsulated in liposome for the first time 1243 by both probe sonication and extrusion methods. However, 1244 the extrusion method produced a more stable liposome both 1245 when dispersed in $\mathrm{ddH}_{2} \mathrm{O}$ and in culture medium. The 1246 spectra analysis confirms probe sonication produced a less 1247 successful encapsulation based on the similarity between PB- 1248 Lipo-AgNP and AgNP spectra characteristics. Ex-Lipo- 1249 AgNP on the other hand had a different spectra analysis 1250 which is believed to be as a result of the shielding effect of 1251 the liposome bilayer. In addition, Ex-Lipo-AgNP exhibited a 1252 more controlled AgNP release compared with the PB-Lipo- 1253 AgNP which showed an initial burst release. Cell viability 1254 studies indicated that Ex-Lipo-AgNP exhibited higher cyto- 1255 toxic effect in comparison to PB-Lipo-AgNP and uncoated 1256 AgNP at similar concentrations. This may have been due to 1257 the stable characteristic of Ex-Lipo-AgNP facilitating an 1258 effective delivery of the nanoparticle into the cell. As such, 1259 extrusion method offers a more reliable way for encapsuch 1260 offers a more reliable way for encapsulating AgNP in liposome with repetitive characteristics and enhanced cytotoxicity. This provides with potential of achieving cytotoxicity at lower concentrations compared to those currently in application limiting possible exposures.

\section{Disclosure statement}

No potential conflict of interest was reported by the authors.

\section{Funding}

1271

1272

This research work and Azeez Yusuf was supported by the Dublin 1273 Institute of Technology's Fiosraigh dean of graduate's research fellow- 1274 ship. Alan Casey acknowledges the support of the Science Foundation 1274 Ireland Principal Investigator Award 11/PI/1108.

\section{References}

[1] Polivkova, M.; Hubacek, T.; Staszek, M.; Svorcik, V.; Siegel, J. 1280 Antimicrobial Treatment of Polymeric Medical Devices by 1281 Silver Nanomaterials and Related Technology. Int. J. Mol. Sci. 1282 2017, 18, pii: E419.

[2] Carbone, M.; Donia, D. T.; Sabbatella, G.; Antiochia, R. Silver Nanoparticles in Polymeric Matrices for Fresh Food Packaging. J. King Saud Univ. - Sci. 2016, 28, 273-279. DOI: 10.1016/ j.jksus.2016.05.004

[3] Asharani, P.; Sethu, S.; Lim, H. K.; Balaji, G.; Valiyaveettil, S.; 1287 Hande, M. P. Differential Regulation of Intracellular Factors 1288 Mediating Cell Cycle, DNA Repair and Inflammation following 1289 Exposure to Silver Nanoparticles in Human Cells. Genome 1290 Integr. 2012, 3, 2. DOI: 10.1186/2041-9414-3-2.

[4] Juarez-Moreno, K.; Gonzalez, E. B.; Giron-Vazquez, N.; 1291 Chavez-Santoscoy, R. A.; Mota-Morales, J. D.; Perez-Mozqueda, 1292 L. L.; Garcia-Garcia, M. R.; Pestryakov, A.; Bogdanchikova, N. 1293 Comparison of Cytotoxicity and Genotoxicity Effects of Silver 1294 
Nanoparticles on Human Cervix and Breast Cancer Cell Lines. Hum. Exp. Toxicol. 2017, 36, 931-948. DOI: 10.1177/ 0960327116675206.

[5] Foldbjerg, R.; Dang, D. A.; Autrup, H. Cytotoxicity and Genotoxicity of Silver Nanoparticles in the Human Lung Cancer Cell Line, A549. Arch. Toxicol. 2011, 85, 743-750. DOI: 10.1007/s00204-010-0545-5.

[6] Foldbjerg, R.; Irving, E. S.; Hayashi, Y.; Sutherland, D. S.; Thorsen, K.; Autrup, H.; Beer, C. Global Gene Expression Profiling of Human Lung Epithelial Cells after Exposure to Nanosilver. Toxicol. Sci. 2012, 130, 145-157. DOI: 10.1093/toxsci/kfs225.

[7] León-Silva, S.; Fernández-Luqueño, F.; López-Valdez, F. Silver Nanoparticles (AgNP) in the Environment: A Review of Potential Risks on Human and Environmental Health. Water, Air, Soil Pollut. 2016, 227, 306. DOI: 10.1007/s11270-016-3022-9.

[8] Agassandian, M.; Mallampalli, R. K. Surfactant Phospholipid Metabolism. Biochim. Biophys. Acta 2013, 1831, 612-625. DOI: 10.1016/j.bbalip.2012.09.010.

[9] Briuglia, M. L.; Rotella, C.; McFarlane, A.; Lamprou, D. A. Influence of Cholesterol on Liposome Stability and on In Vitro Drug Release. Drug Deliv. Transl. Res. 2015, 5, 231-242. DOI: 10.1007/s13346-015-0220-8.

[10] Wu, Q.; Jin, R.; Feng, T.; Liu, L.; Yang, L.; Tao, Y.; Anderson, J. M.; Ai, H.; Li, H. Iron Oxide Nanoparticles and Induced Autophagy in Human Monocytes. Int. J. Nanomed. 2017, 12, 3993-4005. DOI: 10.2147/IJN.S135189.

[11] Shen, J.; Burgess, D. J. In Vitro Dissolution Testing Strategies for Nanoparticulate Drug Delivery Systems: Recent Developments and Challenges. Drug Deliv. And Transl. Res. 2013, 3, 409-415. DOI: 10.1007/s13346-013-0129-z.

[12] Uggeri, J.; Gatti, R.; Belletti, S.; Scandroglio, R.; Corradini, R.; Rotoli, B. M.; Orlandini, G. Calcein-AM Is a Detector of Intracellular Oxidative Activity. Histochem. Cell Biol. 2000, 122, 499-505. DOI: $10.1007 /$ s00418-004-0712-y.

[13] Becaro, A. A.; Jonsson, C. M.; Puti, F. C.; Siqueira, M. C.; Mattoso, L. H.; Correa, D. S.; Ferreira, M. D. Toxicity of PVAStabilized Silver Nanoparticles to Algae and Microcrustaceans. Environ. Nanotechnol. Monit. Manage. 2015, 3, 22-29. DOI: 10.1016/j.enmm.2014.11.002.

[14] Cheon, J. Y.; Kang, Y. O.; Park, W. H. Formation of Ag Nanoparticles in PVA Solution and Catalytic Activity of Their Electrospun PVA Nanofibers. Fibers Polym. 2015, 16, 840-849. DOI: 10.1007/s12221-015-0840-0.

[15] Dong, X.; Ji, X.; Wu, H.; Zhao, L.; Li, J.; Yang, W. Shape Control of Silver Nanoparticles by Stepwise Citrate Reduction. J. Phys. Chem. C 2009, 113, 6573-6576. DOI: 10.1021/jp900775b.

[16] Djokic, S. Synthesis and Antimicrobial Activity of Silver Citrate Complexes. Bioinorg. Chem. Appl. 2008, 2008, 436458.

[17] Maruyama, K. Intracellular Targeting Delivery of Liposomal Drugs to Solid Tumors Based on EPR Effects. Adv. Drug Deliv. Rev. 2011, 63, 161-169. DOI: 10.1016/j.addr.2010.09.003.

[18] Shieh, Y. T.; Chen, J. Y.; Twu, Y. K.; Chen, W. J. The Effect of $\mathrm{pH}$ and Ionic Strength on the Dispersion of Carbon Nanotubes in Poly (Acrylic Acid) Solutions. Polym. Int. 2012, 61, 554-559. DOI: $10.1002 /$ pi.3203.

[19] Zuber, A.; Purdey, M.; Schartner, E.; Forbes, C.; van der Hoek, B.; Giles, D.; Abell, A.; Monro, T.; Ebendorff-Heidepriem, H. Detection of Gold Nanoparticles with Different Sizes Using Absorption and Fluorescence Based Method. Sens. Actuat. B: Chem. 2016, 227, 117-127. DOI: 10.1016/j.snb.2015.12.044.

[20] Sabuncu, A. C.; Grubbs, J.; Qian, S.; Abdel-Fattah, T. M.; Stacey, M. W.; Beskok, A. Probing Nanoparticle Interactions in Cell Culture Media. Colloids Surf. B Biointerfaces 2012, 95, 96-102. DOI: 10.1016/j.colsurfb.2012.02.022.

[21] Liao, W. S.; Chen, X.; Yang, T.; Castellana, E. T.; Chen, J.; Cremer, P. S. Benchtop Chemistry for the Rapid Prototyping of Label-Free Biosensors: Transmission Localized Surface Plasmon Resonance Platforms. Biointerphases 2009, 4, 80-85. DOI: 10.1116/1.3284738.
[22] Monteiro, N.; Martins, A.; Reis, R. L.; Neves, N. M. Liposomes in Tissue Engineering and Regenerative medicine. J. R. Soc. Interface . 2014, 11, 20140459.DOI: 10.1098/rsif.2014.0459.

[23] Ueno, T.; Tsuchiya, H.; Mizogami, M.; Takakura, K. Local Anesthetic Failure Associated with Inflammation: verification of the Acidosis Mechanism and the Hypothetic Participation of Inflammatory Peroxynitrite. J. Inflamm. Res. 2008, 1, 41-48.

[24] Huber, V.; Camisaschi, C.; Berzi, A.; Ferro, S.; Lugini, L.; Triulzi, T.; Tuccitto, A.; Tagliabue, E.; Castelli, C.; Rivoltini, L.; et al. Cancer Acidity: An Ultimate Frontier of Tumor Immune Escape and a Novel Target of Immunomodulation. Semin. Cancer Biol. 2017, 43, 74-89. DOI: 10.1016/j.semcancer.2017.03.001.

[25] Som, A.; Bloch, S.; Ippolito, J. E.; Achilefu, S. Acidic Extracellular $\mathrm{pH}$ of Tumors Induces Octamer-Binding Transcription Factor 4 Expression in Murine Fibroblasts in Vitro and in Vivo. Sci. Rep. 2016, 6, 27803. DOI: 10.1038/srep27803.

[26] Jamuna-Thevi, K.; Bakar, S.; Ibrahim, S.; Shahab, N.; Toff, M. Quantification of Silver Ion Release, In Vitro Cytotoxicity and Antibacterial Properties of Nanostuctured Ag Doped TiO2 Coatings on Stainless Steel Deposited by RF Magnetron Sputtering. Vacuum. 2011, 86, 235-241. DOI: 10.1016/ j.vacuum.2011.06.011.

[27] Rivadeneira, J.; Di Virgilio, A.; Audisio, M.; Boccaccini, A.; Gorustovich, A. Evaluation of Antibacterial and Cytotoxic Effects of Nano-Sized Bioactive Glass/Collagen Composites Releasing Tetracycline Hydrochloride. J. Appl. Microbiol. 2014, 116, 1438-1446. DOI: 10.1111/jam.12476.

[28] Hua, X.; Tan, S.; Bandara, H. M.; Fu, Y.; Liu, S.; Smyth, H. D. Externally Controlled Triggered-Release of Drug from PLGA Micro and Nanoparticles. PLoS One 2014, 9, e114271. DOI: 10.1371/journal.pone.0114271.

[29] Singh, R.; Lillard, J. W. Nanoparticle-Based Targeted Drug Delivery. Exp. Mol. Pathol. 2009, 86, 215-223. DOI: 10.1016/ j.yexmp.2008.12.004.

[30] Tan, J. M.; Karthivashan, G.; Arulselvan, P.; Fakurazi, S.; Hussein, M. Z. Sustained Release and Cytotoxicity Evaluation of Carbon Nanotube-Mediated Drug Delivery System for Betulinic Acid. J. Nanomater. 2014, 2014, 1. DOI: 10.1155/2014/862148.

[31] Ruttala, H. B.; Ko, Y. T. Liposome Encapsulated AlbuminPaclitaxel Nanoparticle for Enhanced Antitumor Efficacy. Pharm. Res. 2015, 32, 1002-1016. DOI: 10.1007/s11095-014-1512-2.

[32] Mrakovcic, M.; Meindl, C.; Roblegg, E.; Frohlich, E. Reaction of Monocytes to Polystyrene and Silica Nanoparticles in shortterm and long-term exposures. Toxicol. Res. (Camb) 2014, 3, 86-97. DOI: 10.1039/C3TX50112D.

[33] Rueda-Romero, C.; Hernandez-Perez, G.; Ramos-Godinez, P.; Vazquez-Lopez, I.; Quintana-Belmares, R. O.; Huerta-Garcia, E.; Stepien, E.; Lopez-Marure, R.; Montiel-Davalos, A.; et al. Titanium Dioxide Nanoparticles Induce the Expression of Early and Late Receptors for Adhesion Molecules on Monocytes. Part Fibre Toxicol. 2016, 13, 36.

[34] Robbins, G. R.; Roberts, R. A.; Guo, H.; Reuter, K.; Shen, T.; Sempowski, G. D.; McKinnon, K. P.; Su, L.; DeSimone, J. M.; Ting, J. P.-Y.; et al. Analysis of Human Innate Immune Responses to PRINT Fabricated Nanoparticles with Cross Validation Using a Humanized Mouse Model. Nanomed. Nanotechnol. Biol. Med. 2015, 11, 589-599. DOI: 10.1016/j.nano.2014.11.010.

[35] Lameijer, M. A.; Tang, J.; Nahrendorf, M.; Beelen, R. H. J.; Mulder, W. J. M. Monocytes and Macrophages as Nanomedicinal Targets for Improved Diagnosis and Treatment of Disease. Expert Rev. Mol. Diagn. 2013, 13, 567-580. DOI: 10.1586/14737159.2013.819216.

[36] Foged, C.; Franzyk, H.; Bahrami, S.; Frokjaer, S.; Jaroszewski, J. W.; Nielsen, H. M.; Olsen, C. A. Cellular Uptake and Membrane-Destabilising Properties of Alpha-Peptide/Beta-Peptoid Chimeras: Lessons for the Design of New Cell-Penetrating Peptides. Biochim. Biophys. Acta 2008, 1778, 2487-2495. DOI: 10.1016/j.bbamem.2008.06.020. 